\title{
LINCing Nuclear Mechanobiology With Skeletal Muscle Mass and Function
}

\author{
Maria J. A. van Ingen ${ }^{1}$ and Tyler J. Kirby ${ }^{2 *}$ \\ ${ }^{1}$ Biomolecular Sciences, Faculty of Science, Vrije Universiteit Amsterdam, Amsterdam, Netherlands, ${ }^{2}$ Department \\ of Physiology, Amsterdam Cardiovascular Sciences, Amsterdam Movement Sciences, Amsterdam UMC, Amsterdam, \\ Netherlands
}

Skeletal muscle demonstrates a high degree of adaptability in response to changes in mechanical input. The phenotypic transformation in response to mechanical cues includes changes in muscle mass and force generating capabilities, yet the molecular pathways that govern skeletal muscle adaptation are still incompletely understood. While there is strong evidence that mechanotransduction pathways that stimulate protein synthesis play a key role in regulation of muscle mass, there are likely additional mechano-sensitive mechanisms important for controlling functional muscle adaptation. There is emerging evidence that the cell nucleus can directly respond to mechanical signals (i.e., nuclear mechanotransduction), providing a potential additional level of

OPEN ACCESS

Edited by:

Yuji Ogura,

St. Marianna University School

of Medicine, Japan

Reviewed by:

Jung Yul Lim,

University of Nebraska-Lincoln,

United States

G. W. Luxton,

University of Minnesota, United States

${ }^{*}$ Correspondence:

Tyler J. Kirby

t.kirby@amsterdamumc.nl

Specialty section:

This article was submitted to

Signaling,

a section of the journal

Frontiers in Cell and Developmental

Biology

Received: 03 April 2021

Accepted: 25 June 2021

Published: 21 July 2021

Citation:

van Ingen MJA and Kirby TJ

(2021) LINCing Nuclear

Mechanobiology With Skeletal Muscle

Mass and Function.

Front. Cell Dev. Biol. 9:690577.

doi: 10.3389/fcell.2021.690577 cellular regulation for controlling skeletal muscle mass. The importance of nuclear mechanotransduction in cellular function is evident by the various genetic diseases that arise from mutations in proteins crucial to the transmission of force between the cytoskeleton and the nucleus. Intriguingly, these diseases preferentially affect cardiac and skeletal muscle, suggesting that nuclear mechanotransduction is critically important for striated muscle homeostasis. Here we discuss our current understanding for how the nucleus acts as a mechanosensor, describe the main cytoskeletal and nuclear proteins involved in the process, and propose how similar mechanoresponsive mechanisms could occur in the unique cellular environment of a myofiber. In addition, we examine how nuclear mechanotransduction fits into our current framework for how mechanical stimuli regulates skeletal muscle mass.

Keywords: mechanotransduction, nucleus, LINC complex, muscle mass, muscle adaptation, nuclear lamina, nesprins

\section{INTRODUCTION}

Skeletal muscle cells have the remarkable ability to adapt their size and force-generating capacity in response to changes in mechanical load. As a response to mechanical stimuli, skeletal muscle cells alter their protein metabolism primarily by modulating protein synthesis rates, with the importance of protein synthesis in determining muscle mass being well documented

Abbreviations: BAF, barrier-to-autointegration factor; $\mathrm{CIP}$, cardiac Islet-1 interaction protein; $\mathrm{CH}$, calponin homology domain; CPLA2, phospholipase A2; ECM, extracellular matrix; ER, endoplasmic reticulum; INM, inner nuclear membrane; KASH, Klarsicht, ANC-1, Syne homology; LAD, lamina-associated domain; LEM, LAP2-emerin-MAN1 domain; LINC, linkers of nucleoskeleton and cytoskeleton; NE, nuclear envelope; nesprin, nuclear envelope spectrin repeat protein; NPC, nuclear pore complex; ONM, outer nuclear membrane; PCM1, pericentriolar material 1; PNS, perinuclear space; Pol-II, RNApolymerase II; PPAR $\gamma$, peroxisome proliferators-activated receptors $\gamma$; SUN1/2, Sad1p-UNC-84 domain 1 and 2 proteins; TAZ, transcriptional coactivator with PDZ-binding motif; YAP, Yes-associated protein. 
(Bodine et al., 2001; Marcotte et al., 2015; You et al., 2019). The mechanosensitive biochemical signaling pathways that regulate protein synthesis, such as mTORC1, MAPK, WNT/ $\beta$-catenin, and YAP/TAZ, have been studied intensively over the past years and have been summarized in several excellent reviews (Bamman et al., 2018; Watt et al., 2018; Sartori et al., 2021). Our framework for how mechanotransduction, the conversion of mechanical forces into a cellular response, controls skeletal muscle mass is primarily through these biochemical signaling events. Traditionally the cell nucleus has been viewed as a passive organelle, simply serving as a reservoir for DNA and requiring cytosolic events to dictate nuclear responses. However, recent evidence has emerged showing that the nucleus itself can act as a mechanosensitive element, directly translating mechanical forces into a cellular response (Kirby and Lammerding, 2018; Aureille et al., 2019; Stephens et al., 2019) in a process termed "nuclear mechanotransduction." The mechanisms by which nuclear mechanotransduction impacts cellular processes include nuclear envelope stretching (Enyedi et al., 2016; Lomakin et al., 2020; Venturini et al., 2020), modification of nuclear envelope proteins (Guilluy et al., 2014), histone modifications and chromatin architecture (Le et al., 2016; Nava et al., 2020), transcription factor localization (Elosegui-Artola et al., 2017; Cosgrove et al., 2021), and gene expression (Tajik et al., 2016). Limited evidence exists for a putative role of nuclear mechanotransduction in regulating muscle homeostasis and adaptation (Piccus and Brayson, 2020; Jabre et al., 2021), despite the clear link between mechanical loading and skeletal muscle mass. Much of the evidence linking nuclear mechanotransduction to skeletal muscle function comes from the study of genetic diseases, where mutations in key proteins involved in nuclear mechanotransduction result in severe dystrophic phenotypes primarily affecting skeletal and cardiac muscle (Puckelwartz et al., 2010; McGlory and Phillips, 2015; Zhou et al., 2017; Piekarowicz et al., 2019; Heller et al., 2020). While these tissue-specific disease phenotypes suggest that nuclear mechanotransduction may be important in the context of normal muscle physiology, we still have limited knowledge regarding if and how myonuclei respond to the various mechanical forces present in skeletal muscle, and how this might integrate with other well-characterized mechanosensitive signaling cascades to ultimately control muscle mass and function. In this review, we will highlight the complexes involved in nuclear mechanotransduction, examine the latest evidence for nuclear mechanotransduction in cellular adaptation, and propose mechanisms for how nuclear mechanotransduction could play a role in the regulation of muscle mass.

\section{COMPLEXES INVOLVED IN NUCLEAR MECHANOTRANSDUCTION}

Recent evidence demonstrates that a nucleus is able to "sense" mechanical forces and elicit various biological responses (Kirby and Lammerding, 2018; Janota et al., 2020; Lomakin et al., 2020; Venturini et al., 2020). Mechanical forces can be transmitted to the nucleus from the exterior environment through cellular adhesion complexes (Maniotis et al., 1997; Tajik et al., 2016), intracellular generated forces (Earle et al., 2020), physical compression (Lomakin et al., 2020; Venturini et al., 2020), or osmotic changes (Enyedi et al., 2016; Petridou et al., 2017). Thus, one important consideration is that differences in force application may dictate the specificity of the response. The cytoskeleton is made up out of three main polymers; actin filaments, microtubules and intermediate filaments. Together, they organize the contents of the cell, enable organelle movement, dictate the cells' motility and shape, and connect the cell physically and biochemically to the external environment. One mechanism by which mechanical forces are transduced to the nucleus is through an intercellular network that physically connects the cytoskeleton to the nucleoskeleton via the LInker of Nucleoskeleton and Cytoskeleton (LINC) complex (Guilluy et al., 2014; Hao and Starr, 2019; Janota et al., 2020; Wong et al., 2021). The significance of this physical connection is that mechanical signals can propagate at speeds $12.5-25$ times faster than passive diffusion or molecular motor-based signaling (Maurer and Lammerding, 2019), facilitating an extremely rapid cellular response. The LINC complex is a group of proteins that transverse through the nuclear envelope (NE), forming a bridge between the cytoskeleton and the nucleoskeleton (Lombardi et al., 2011; Hao and Starr, 2019). The LINC complex consists of two classes of proteins; the Klarsicht/ANC-1/SYNE homology (KASH) domain-containing proteins and the Sad-1 and UNC84 (SUN) domain-containing proteins. The KASH family of proteins is composed of six members: nesprin-1 (encoded by SYNE1), nesprin-2 (encoded by SYNE2), nesprin-3 (encoded by SYNE3), nesprin-4 (encoded by SYNE4), Jaw1/LRMP (encoded by JAW1), and KASH5 (encoded by KASH5) (Horn et al., 2013b; Rajgor and Shanahan, 2013; Kozono et al., 2018; Janin and Gache, 2018; Zhou et al., 2018). Nesprins localize to the outer nuclear membrane (ONM) and interact with SUN proteins in the perinuclear space (PNS). Multiple nesprin-1 and -2 isoforms can be generated through alternative transcription and splicing, with the so-called giant isoforms interacting with actin via their calponin homology $(\mathrm{CH})$ domain and/or microtubules via a LEWD motif-kinesin-1 interaction (Wilson and Holzbaur, 2015). In addition, smaller isoforms can interact with microtubules via various interacting partners, including AKAP450 (aka AKAP9) (Gimpel et al., 2017; Janin and Gache, 2018). Nesprin-3 interacts with intermediate filaments via the cytoskeletal linker protein plectin (Wilhelmsen et al., 2005; Wiche et al., 2015). In the case of striated muscle, the major intermediate filament protein is desmin (Heffler et al., 2020) and the major nuclear-associated plectin isoform is plectin-1 (Staszewska et al., 2015). Nesprin-4 interacts with microtubules via kinesin-1; however, its expression is restricted mainly to secretory epithelia (Roux et al., 2009) and outer hair cells of the inner ear (Horn et al., 2013a). The SUN family of proteins comprise five family members; of these, SUN1 and SUN2 are the most widely expressed (Malone et al., 1999; Crisp et al., 2005). SUN proteins form a trimeric complex that span the inner nuclear membrane (INM) and into the PNS, where their SUN domain interacts with the C-terminal KASH domain of the nesprins (Jahed et al., 2019). The N-terminus of the SUN proteins associates with nucleoplasmic structures, including the nuclear 
lamina (Crisp et al., 2005; Haque et al., 2006) and chromatin (Horn et al., 2013b).

Within the INM reside members of the LAP2-emerin-MAN1 (LEM) domain family of proteins (Barton et al., 2015). Of these, emerin is the most studied in the context of skeletal muscle biology, due to mutations in emerin giving rise to Emery Dreifuss muscular dystrophy (Heller et al., 2020). Emerin can bind a chromatin-interacting protein named barrier-to-autointegration factor (BAF) (Samson et al., 2018), small isoforms of nesprin1 and nesprin-2 (Mislow et al., 2002; Zhang et al., 2005; Wheeler et al., 2007), and SUN proteins (Haque et al., 2010). Additionally, emerin binds to the nuclear lamina, enabling it to retain chromatin close to the NE during cell interphase (Berk et al., 2013; Samson et al., 2018). Furthermore, due to the physical connection to the LINC complex (Haque et al., 2006) and LEM domain proteins (Barton et al., 2015), the nuclear lamina serves as one of the major integration sites for nuclear mechanotransduction. The nuclear lamina is a filamentous meshwork of A-type lamins (lamins A and C) and B-type lamins (lamins B1 and B2). The lamina lies just underneath the INM and interacts with LEM domain proteins (Gesson et al., 2014), nuclear pore complexes (NPCs) (Xie et al., 2016), transcription factors (Ivorra et al., 2006), and chromatin through lamina-associated domains (LADs) present in the genome (van Steensel and Belmont, 2017). The nuclear lamina, along with heterochromatin, provides mechanical stability to the nucleus (Lammerding et al., 2006; Stephens et al., 2017), and the expression of lamin A scales with tissue stiffness (Swift et al., 2013). Collectively, the cytoskeleton - LINC complex lamina - chromatin interaction network can serve as a powerful mechanism to convert mechanical signals into a cellular response.

The composition and function of the LINC complex have been studied extensively in mononucleated adherent cells, including fibroblasts, endothelial cells, and enucleated mammalian cells (cytoplasts) (Lombardi et al., 2011; Anno et al., 2012; Graham et al., 2018; Bouzid et al., 2019). Skeletal muscle cells have a unique, highly structured cytoskeletal organization, specifically designed for high force generation. Thus, the nucleo-cytoskeletal interactions in myofibers need to be arranged to accommodate this specialized cellular function (Figure 1). Moreover, myofibers are multinucleated syncytial cells with an ordered arrangement of hundreds of myonuclei located on the periphery of the myofiber, with additional myonuclei being added during muscle growth via the fusion of satellite cells (Snijders et al., 2015; Murach et al., 2017). The importance of the LINC complex in skeletal muscle has been primarily examined for its role in nuclear movement and organization during myogenesis (Zhang et al., 2010; Gimpel et al., 2017; Stroud et al., 2017); however, it may have different functions in fully mature myofibers. For example, Nesprin- $1 \alpha 2$ associates with kinesin-1 at myotube outer nuclear membranes (Gimpel et al., 2017), but is restricted to neuromuscular junction nuclei in adult muscle (Holt et al., 2019). The current body of research about the organization and importance of the LINC complex in adult striated muscle cells comes from recent studies in cardiomyocytes (Heffler et al., 2020); however, cardiomyocytes are either mono- or bi-nucleated, with the nucleus located in the center of the cell (Janin and Gache, 2018).
In cardiac cells, microtubules interact with the nucleus via AKAP6 and AKAP9 (Vergarajauregui et al., 2020); AKAP9 serves an additional function in skeletal muscle cells, where it is required for microtubule-mediated nuclear migration (Gimpel et al., 2017). Interestingly, another microtubule-organizing protein, pericentriolar material 1 (PCM1), is enriched on myonuclei in adult muscle (Winje et al., 2018). Recently, Liu et al. (2020) discovered that an alternatively spliced version of Cardiac Islet1 Interaction Protein (CIP) interacts with several LINC complex proteins and plays a role in microtubule-mediated nuclear movement during differentiation. However, the functional role of PCM1 and CIP in myonuclear force transmission in adult muscle is still not known.

Microtubules play an important role in mechanotransduction in cardiac cells (Kerr et al., 2015; Vergarajauregui et al., 2020), where they form a cage-like structure around the nucleus. Similar cage-like structures are observed in skeletal muscle cells (Becker et al., 2020; Earle et al., 2020), although the significance of these microtubule-myonuclear interactions on nuclear morphology and mechanotransduction requires additional investigation. Similarly, the desmin - plectin - nesprin3 interlinkage (Wilhelmsen et al., 2005; Ketema et al., 2007; Wiche et al., 2015) appears to play a role in maintaining nuclear morphology (Heffler et al., 2020) and mechanotransduction (Palmisano et al., 2015; Staszewska et al., 2015), making this complex an intriguing candidate in the context of skeletal muscle adaptation. An important consideration is that the arrangement of the LINC complex, nuclear lamina, and NE could deviate between cardiac and skeletal muscle - and even more distinctively compared to previously studied non-muscle celllines. We suggest that this warrants additional investigations into how the nucleus interacts with cytoskeleton and other organelles (ER, golgi, etc.) in skeletal muscle cells. Moreover, it is still not clear how newly acquired myonuclei integrate into the highly complex and ordered cytoskeletal network and what LINC complex reorganization must occur to facilitate this process. Finally, the contribution of specific proteins in nucleo-cytoskeletal coupling will have to be considered when determining what forces may be transmitted to myonuclei during passive (stretch) and active (contractile) force generation.

\section{EVIDENCE FOR NUCLEAR MECHANOTRANSDUCTION IN NON-SKELETAL MUSCLE CELLS}

The first evidence of nuclear mechanotransduction came in the 1990s, when pioneering work by the Ingber laboratory showed that nuclei are "hard-wired" to their surrounding cytoplasm and that forces applied to either integrins or the cytoskeleton could elicit a physical response from the nucleus (Maniotis et al., 1997). Since those seminal studies, significant work has gone into trying to dissect which cellular responses to mechanical signals can be attributed to direct responses by nuclei themselves. Supporting evidence for the importance of nuclear mechanics come from disease-causing mutations in proteins involved in nuclear mechanotransduction 


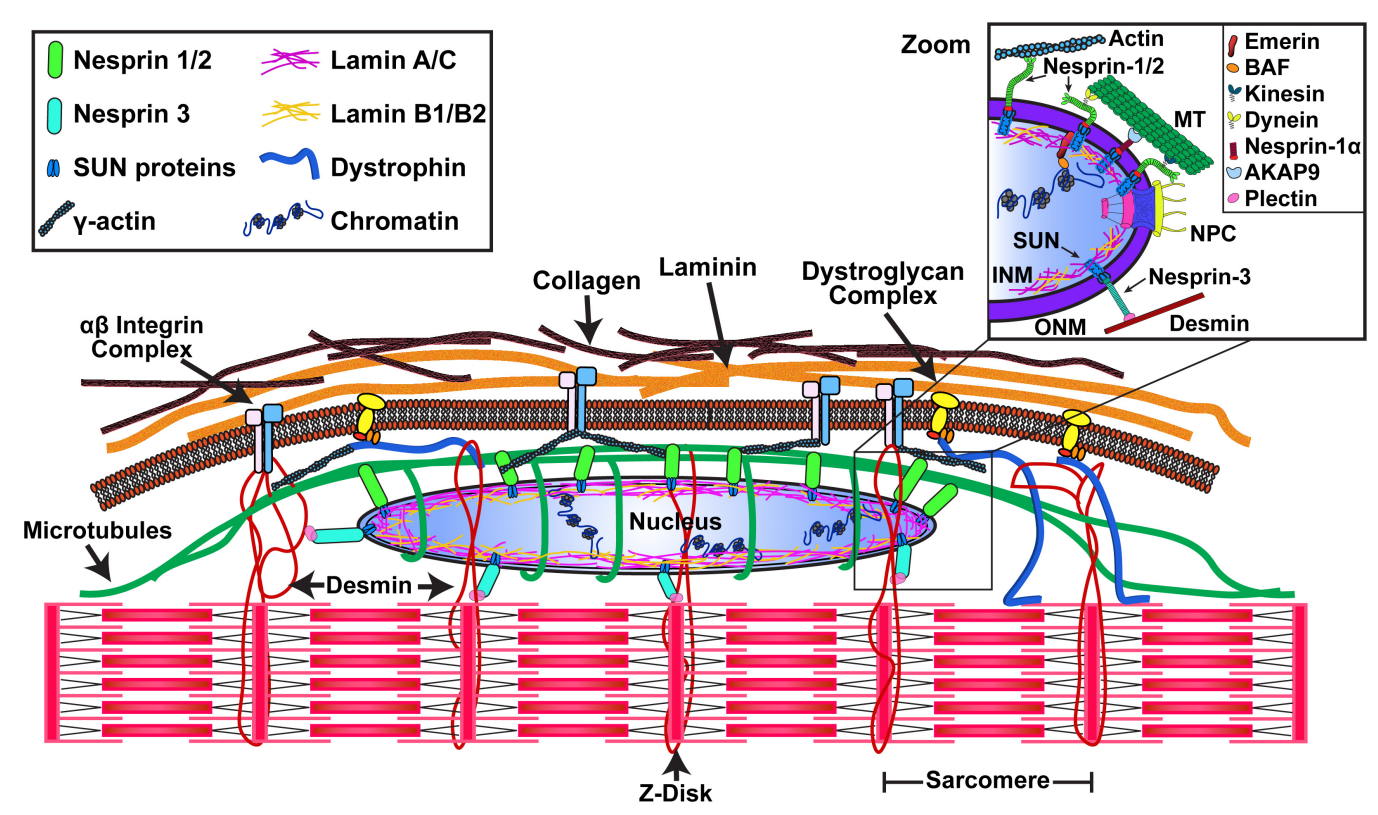

FIGURE 1 | Cytoskeletal organization around myonuclei provides a mechanism for nuclear mechanotransduction. Cytoskeletal proteins (microtubules, desmin, and $\gamma$-actin) are directly connected to myonuclei via the LINC (Linker of Nucleus and Cytoskeleton) complex. The LINC complex is composed of nesprin and SUN proteins, with SUN proteins interacting with the nuclear lamina (composed of A- and B-type lamins). Chromatin is tethered to the periphery of the nucleus via the nuclear lamina, providing a mechanism for cytoskeletal mechanical signals to be transmitted directly to the nuclear interior and chromatin. Inset: The SUN components of the LINC complex interact with NPCs. Emerin binds to the nuclear lamina and the chromatin-interacting protein BAF. The giant isoforms of Nesprin-1/2 interact with actin through their $\mathrm{CH}$ domain and microtubules via kinesin-1 and dynein (Zhu et al., 2017), while Nesprin-1 $\alpha$ uses AKAP9. Nesprin-3 binds to desmin via plectin. Modified from Kirby (2019).

(Piekarowicz et al., 2019; Donnaloja et al., 2020; Heller et al., 2020). Though the underlying molecular mechanisms by which these proteins regulate tissue homeostasis have not yet been fully elucidated, nuclear mechanotransduction has been shown to induce chromatin rearrangement (Le et al., 2016; Nava et al., 2020), NE-unfolding (Enyedi et al., 2016; Lomakin et al., 2020; Venturini et al., 2020), the post-translational modification of nuclear proteins (Guilluy et al., 2014), transcription factor translocation (Elosegui-Artola et al., 2017), and gene expression (Tajik et al., 2016).

\section{Chromatin Stretching/Modifications}

One proposed mechanism for how mechanical forces transmitted to the nucleus can lead directly to a cellular response is through changes in chromatin organization or accessibility to transcription factors. Condensed chromatin, or heterochromatin, that is localized to the nuclear periphery is often adjacent to and makes contact with the nuclear lamina at LADs (van Steensel and Belmont, 2017). DNA is wrapped around histones, forming tightly compacted heterochromatin, inaccessible for transcription, along with less condensed euchromatin (Janssen et al., 2018). Moreover, A-type lamins, in cooperation with LEMdomain proteins, are critical for tethering heterochromatin to the NE (Solovei et al., 2013); thus, these physical interactions between chromatin and the nuclear lamina can allow forces to be transmitted to chromatin. To this end, Tajik et al. (2016) showed that local surface force at the plasma membrane, acting through the LINC complex, can directly stretch the chromatin and induce a rapid increase in transcription. This force-induced chromatin stretching and transcriptional upregulation is sensitive to both levels of $\mathrm{H} 3 \mathrm{~K} 9 \mathrm{me} 3$ and force application frequency, where low $\mathrm{H} 3 \mathrm{~K} 9 \mathrm{me} 3$ levels and low frequency are required for sufficient chromatin stretching and subsequent recruitment of RNA-polymerase II (Pol II) (Sun et al., 2020). Thus, epigenetic alterations to chromatin may serve as a mechanism for determining the specificity of the transcriptional response to nuclear force transmission. Recently, Nava et al. (2020) found that stretching of the nuclear membrane results in the rapid loss of histone methylation at $\mathrm{H} 3 \mathrm{~K} 9$ and $\mathrm{H} 3 \mathrm{~K} 27$, producing a more deformable nucleus that is protected from force-induced damage. Intriguingly, prolonged mechanical strain leads to large-scale chromatin rearrangements and the replacement of $\mathrm{H} 3 \mathrm{~K} 9 \mathrm{me} 2,3$ with $\mathrm{H} 3 \mathrm{~K} 27 \mathrm{me}$, leading to global transcriptional silencing during stem cell commitment (Le et al., 2016); however, it is unclear if a similar mechanism would occur in a terminally differentiated cell. The frequency and duration of force application on the nucleus appear to be important for determining the change in chromatin organization.

\section{Transcription Factor Localization/Nuclear Pores}

It is suggested that transmission of mechanical forces between the cytoskeleton and nucleoskeleton could directly influence the transport of proteins across the NE through NPCs 
(Donnaloja et al., 2019). NPCs have been shown to interact with both the nuclear lamina (Al-Haboubi et al., 2011; Xie et al., 2016; Kittisopikul et al., 2021) and SUN1 (Liu et al., 2007), providing a mechanism for nuclear force transmission to alter NPC conformation. Work from the Roca-Cusachs laboratory demonstrated that direct application of force to the nucleus causes nuclear deformation, thereby stretching the NPC and allowing for increased import of YAP into the nucleus (EloseguiArtola et al., 2017). Similarly, YAP nuclear entry in response to cyclic strain is impaired when the LINC complex is disrupted in mesenchymal stem cells, (Driscoll et al., 2015), indicating that nuclear mechanotransduction can regulate YAP localization in response to mechanical cues. In addition to altering the permeability of NPCs, mechanical signals can alter NPC localization through the redistribution of LINC complex proteins (Hoffman et al., 2020). The dogma of the NPC being a highly rigid structure has been challenged in recent years (Knockenhauer and Schwartz, 2016; Pulupa et al., 2020). One intriguing hypothesis is that repeated mechanical signals result in the clustering of NPCs at the site of force transmission and physically influence NPC conformation to affect nuclear transport.

Additionally, it has become evident that INM proteins influence the nucleo-cytoplasmic flux of transcription factors. The transcription factor $\beta$-catenin has been shown to be associated with nuclear envelope proteins such as emerin, lamins A/C and the LINC complex (Markiewicz et al., 2006; Tilgner et al., 2009; Neumann et al., 2010; Uzer et al., 2018). Uzer and colleagues found that disabling the LINC complex via codepletion of SUN1/2 impedes the nuclear entry of $\beta$-catenin by limiting its nesprin-mediated interaction with the NE (Uzer et al., 2018). Since the LINC complex plays a critical part in the transmission of applied mechanical force from the cellular surface to the nucleus, Uzer et al., propose a new pathway by which LINC complex-mediated connectivity may play a role in signaling pathways that depend on the nuclear entry of $\beta$ catenin. In addition to the LINC complex, emerin contributes to the regulation of the $\beta$-catenin nuclear flux by binding to cytoplasmic $\beta$-catenin to restrict it from the nucleus (Markiewicz et al., 2006). To further investigate the relationship between $\beta$ catenin and nuclear $\beta$-catenin-binding partners, Tilgner et al. (2009) performed a study focusing on the expression of emerin, A-type lamins, and peroxisome proliferators-activated receptors $\gamma(\operatorname{PPAR} \gamma)$ in preadipocytes and dermal fibroblasts. The authors found that the expression of NE proteins, A-type lamins, and emerin is directly linked to the balance between $\beta$-catenin and the PPAR $\gamma$ signaling to control the adipogenic capacity of the cell. Collectively, nuclear mechanotransduction can influence transcription factor localization to the nucleus, either through direct interactions or by modulating transport across the NPC.

\section{NE and ER Unfolding}

Another mechanism through which the nucleus responds to external forces is via the unfolding and stretching of the NE. Recently, Lomakin et al. (2020) found that migrating immune cells unfold and stretch their NE to adapt to environmental confinement and that enucleated cells show less motility in similar circumstances. Venturini et al. (2020) support these findings, with the demonstration of nuclear deformation due to confinement of primary progenitor stem cells, which leads to INM unfolding and intracellular spatial positioning of the nucleus. Mechanistically, NE stretching leads to the release of calcium; this activates calcium-dependent cytosolic phospholipase A2 (cPLA2), which catalyzes the formation of arachidonic acid to ultimately regulate myosin-II activity (Lomakin et al., 2020; Venturini et al., 2020). This mechanism of nuclear stretch-activation of cPLA2 was first identified by the Niethammer group in response to tissue damage (Enyedi et al., 2016). Similarly, deformation of nuclei with high membrane tension triggers $\mathrm{Ca}^{2+}$ release from the ER to modulate chromatin methylation levels (Nava et al., 2020). Collectively, NE stretch-dependent $\mathrm{Ca}^{2+}$ release is emerging as a powerful intermediary between mechanical inputs and cellular responses. In addition to the effect on calcium release, the amount of NE folding or "wrinkling" is associated with the translocation of mechanosensitive transcription factors, including YAP/TAZ (Cosgrove et al., 2021). One explanation for this altered transcription factor localization could be the accumulation of NPCs in NE invaginations, as has been shown in progeroid cells (Goldman et al., 2004; Röhrl et al., 2021), leading to a physical barrier affecting NPC transport. Lastly, nuclear force transmission has been shown to alter the assembly of the network of A-type lamins, exposing epitopes that are involved in chromatin interactions (Ihalainen et al., 2015). Thus, the extent of NE stretching will be highly dependent on the ability of forces to deform the nucleus, a process determined by the mechanical properties of the nucleus (Lammerding et al., 2006; Stephens et al., 2017).

\section{Biochemical}

Finally, mechanical signals lead to post-translational modifications of INM proteins and A-type lamins resulting in changes to the mechanical properties of the nucleus (Swift et al., 2013; Buxboim et al., 2014; Guilluy et al., 2014; Guilluy and Burridge, 2015; Graham et al., 2018; Gilbert et al., 2019; Ikegami et al., 2020). In isolated mammalian nuclei, pulses of force applied to nesprin 1 result in a decrease in nuclear strain, indicating local nuclear stiffening (Guilluy et al., 2014). The authors found that neither chromatin nor nuclear actin were involved in force response; however, emerin becomes tyrosine phosphorylated by tyrosine kinase Src as a reaction to applied force, strengthening the connection between A-type lamins and the LINC complex. In addition to phosphorylation of emerin, phosphorylation of lamins is a well-known mechanism involved in nuclear lamina assembly and disassembly in cell division. During interphase, A-type lamins phosphorylation is low, allowing for network assembly beneath the INM, whereas phosphorylation results in a shift toward nucleoplasmic localization (Buxboim et al., 2014; Kochin et al., 2014; Ikegami et al., 2020). Studies show that phosphorylation of A-type lamins on Ser22 is associated with soft matrix (Swift et al., 2013), and that their dephosphorylation is caused by myosin-II activity and matrix stiffness (Buxboim et al., 2014). Further experimentation revealed that the phosphodynamics of Ser22 are critical in determining the structural organization and mechanics of nuclei during 
cell spreading (Buxboim et al., 2014). The precise mechanism by which mechanical forces can modulate phosphorylation of nuclear envelope proteins remains under investigation, including whether this process is regulated by altering kinase activities or accessibility of the kinase to cryptic phosphorylation sites within their protein substrates. Nevertheless, the observed mechanically induced phosphorylation implicates a structural role for phosphorylation in mechanotransduction through control of nuclear stiffening and nucleo-cytoskeletal coupling (Maurer and Lammerding, 2019).

\section{POTENTIAL MECHANISMS FOR NUCLEAR MECHANOTRANSDUCTION IN REGULATING MUSCLE MASS AND FUNCTION}

Many structural adaptations occur in skeletal muscle that give rise to changes in muscle mass (Jorgenson et al., 2020), with mechanical loading being a primary driver. Despite this clear association, further work is necessary to determine how structural changes in the muscle may provide feedback to alter the mechanosensitivity of the tissue. Muscle mass is largely governed by protein synthesis rates (Joanisse et al., 2020). However, studies using genetic approaches to manipulate protein turnover and increase muscle mass have failed to demonstrate a concomitant change in force output (Graber et al., 2019; Hunt et al., 2021), suggesting that mechanical input is critical for functional adaptations. To this end, mechanical signals may be important for creating a transcriptional profile that is permissive for changes in muscle mass and function (Phillips et al., 2013; Stokes et al., 2020). Therefore, force transmission to the nucleus could serve as an important regulatory mechanism for altering chromatin organization and transcription factor localization/activity in skeletal muscle cells.

Mislocalization of myonuclei is associated with cellular dysfunction and a range of muscle diseases. An intact LINCcomplex is critical for the localization of the nuclei in skeletal muscle development (Gundersen and Worman, 2013; Janota et al., 2020). For example, nesprin-1 is required for myonuclear anchoring in skeletal muscle (Zhang et al., 2010; Stroud et al., 2017). Double knock-out mouse models of nesprin-1 and nesprin-2 show a cardiomyopathy phenotype alongside changes in nuclear deformation and chromatin decondensation (Banerjee et al., 2014). Moreover, the loss of SUN1 and SUN2 in knockout mouse models demonstrated that nuclear positioning in skeletal muscle cells is disrupted (Lei et al., 2009). Conditional deletion of LAP1, an emerin-interacting protein, causes muscular dystrophy in mice, suggesting that this emerin binding partner is essential for skeletal muscle maintenance and postnatal skeletal muscle growth (Shin et al., 2013, 2014, 2017). In addition to genetically induced disruption of nuclear position, changes in myonuclear morphology have been observed following chronic resistance exercise followed by detraining (Murach et al., 2020) and physiological aging (Brack et al., 2005; Bruusgaard et al., 2006;
Cristea et al., 2010), suggesting that nuclear stability and/or nucleo-cytoskeletal coupling may adapt to changes in mechanical signals. It remains unclear whether this change in morphology is the result of intrinsic myonuclear adaptations or altered LINC complex connections and cytoskeletal forces (Figure 2). Moreover, how this change affects the mechanoresponsiveness of the myonucleus is unknown, as are the potential implications for myofiber homeostasis and adaptation, including nuclear mechanotransduction potentially coordinating a transcriptional profile that complements proteins synthesis changes to influence myofiber structure and function.

It remains to be determined whether mechanoresponsive protein synthetic pathways such as mTORC1, YAP/TAZ, and $\beta$-catenin are influenced by nuclear mechanotransduction in mature muscle cells, and if so, how these processes might synergize to affect muscle function. YAP/TAZ signaling has emerged as a potent regulator of skeletal muscle mass and function (Watt et al., 2015, 2018) and adaptation (Goodman et al., 2015), and has been suggested to be involved in agerelated muscle atrophy (Setiawan et al., 2021). A proteomics study revealed that the expression of YAP is $\sim$ two fold higher in slow-twitch muscle fibers than in fast-twitch muscle fibers from young subjects; in aged subjects, the YAP expression was $\sim 50 \%$ lower in both muscle fiber types compared to younger controls (Murgia et al., 2017). However, YAP/TAZ signaling may be elevated in aged skeletal muscle and associated with changes in the nuclear lamina (Iyer et al., 2021).Together, these results suggest that altered YAP expression and localization via changes in nuclear architecture (Cosgrove et al., 2021) or nuclear mechanotransduction (Driscoll et al., 2015) could play a role in muscle adaptation and age-dependent loss of skeletal muscle mass. Wnt/ $\beta$-catenin signaling has been suggested to be involved in augmenting myofiber hypertrophy in response to increased mechanical load (Armstrong and Esser, 2005; Armstrong et al., 2006) and may be modulated by nuclear access to $\beta$-catenin via the LINC complex (Uzer et al., 2018). The well-characterized mechanosensitive MRTF/SRF pathway was recently shown to be activated in response to muscle contractions and associated with increased protein synthesis (Solagna et al., 2020), with the nuclear retention of MRTF-A being regulated by A-type lamins and emerin (Ho et al., 2013). Lastly, the transcription factor JunB is important for maintaining skeletal muscle mass and can promote hypertrophy (Raffaello et al., 2010). JunB is a member of the AP-1 family of proteins, of which c-Jun and c-Fos have been shown to interact with A-type lamins (Ivorra et al., 2006; Ikegami et al., 2020). Thus, it would be interesting to determine whether similar interactions occur between A-type lamins and JunB in skeletal muscle, and if so, whether the interaction is modulated by mechanical inputs. Collectively, changes in transcription factor localization or activity in response to alterations in nuclear morphology or mechanics may have important implications for regulating the skeletal muscle transcriptome.

Recently, mechanical loading has been shown to induce both DNA and histone modifications in skeletal muscle (McGee and Walder, 2017; Jacques et al., 2019; Solagna et al., 2020; Walden et al., 2020). Specifically, acute mechanical overload in mice results in hypomethylation of genes known to be involved in 


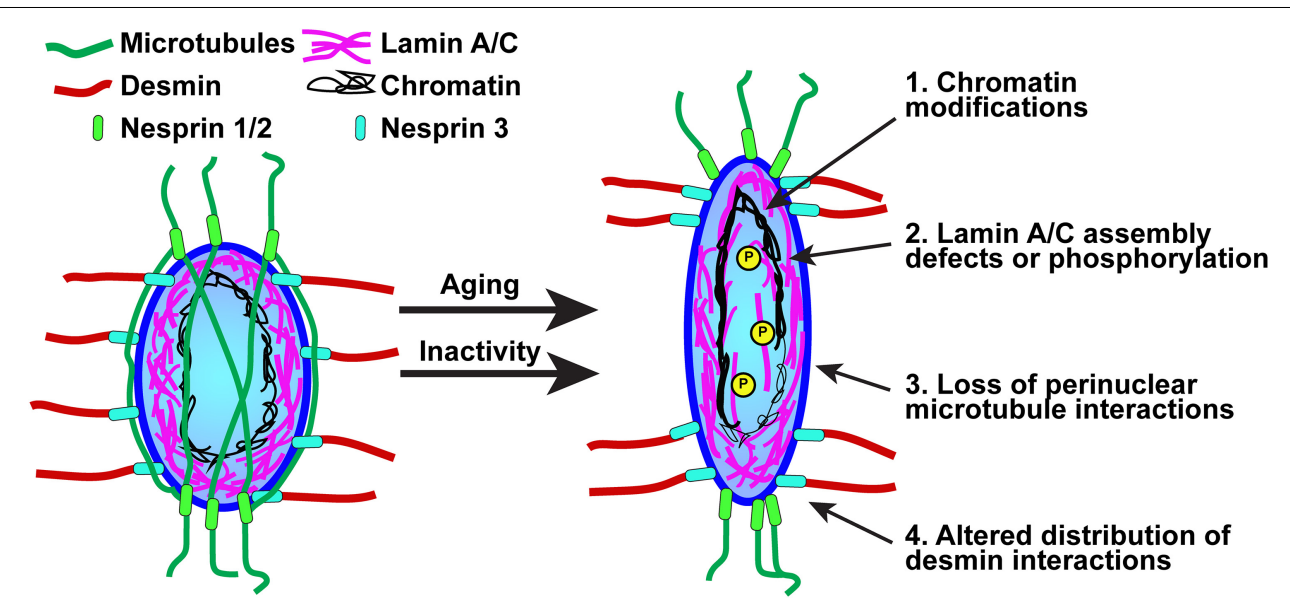

FIGURE 2 | Proposed mechanisms for nuclear-intrinsic and -extrinsic changes that could alter nuclear morphology in response to inactivity or aging. Nuclear stiffness is determined by both A-type lamins expression/assembly and chromatin modifications, specifically the amount of heterochromatin. Phosphorylation of A-type lamins leads to a nucleoplasmic localization and a decrease in nuclear stiffness. Nuclear morphology is also influenced by cytoskeletal forces acting through the LINC complex. Microtubules form a cage-like structure around the nucleus and provide compressive force; thus, elongation could be driven by a decrease in microtubule-nuclear interactions. Loss of desmin or plectin-1 results in more rounded nuclei, suggesting that changes in either the number or arrangement of desmin-nuclear interactions could elicit a change in nuclear morphology.

muscle maintenance, including known regulators of mTORC1 signaling (Walden et al., 2020). Similarly, an acute bout of resistance exercise in humans increases $\mathrm{H} 3 \mathrm{~K} 27 \mathrm{me} 3$ distribution at 16 loci while total $\mathrm{H} 3 \mathrm{~K} 27 \mathrm{me} 3$ levels were unaffected (Lim et al., 2020). Eccentric contraction induces phosphorylation of serine 10 on histone $3(\mathrm{H} 3 \mathrm{~S} 10 \mathrm{ph})$ in mice, with no changes in levels of H3-K9K14ac and H3K4me3 (Solagna et al., 2020). Collectively, these results suggest that changes in mechanical load alter DNA methylation and histone modifications to facilitate a mechanosensitive transcriptional response. During physiological aging there are global changes in histone modifications, including loss of H3K9me3 (Yoshihara et al., 2019) and increased H3K27ac (Zhou et al., 2019), it is possible that age-related alterations in nuclear morphology (Brack et al., 2005; Bruusgaard et al., 2006; Cristea et al., 2010) could promote changes in global chromatin organization. Further investigations are warranted to investigate how these modifications alter the chromatin accessibility in skeletal muscle and whether nuclear mechanotransduction plays a regulatory role in the response to mechanical loading or aging.

\section{IMPORTANT CONSIDERATIONS AND FUTURE DIRECTIONS}

The importance of protein metabolism in establishing a given level of muscle mass is clear; however, changes in protein synthesis do not always correspond to a change in muscle function, suggesting that the effect is dependent on the specific proteins being synthesized. We propose that the impact of nuclear morphology and nuclear mechanotransduction in skeletal muscle homeostasis and adaptation is an area worthy of further investigation. To date, most of the work in skeletal muscle has focused on nuclear abundance as an important determinant of myofiber size and adaptation
(McCarthy et al., 2011; Murach et al., 2017; Psilander et al., 2019; Cramer et al., 2020; Hansson et al., 2020), with almost no focus on the nucleus as being a central player in the mechanotransduction response to mechanical load. The importance of nuclear mechanotransduction and the LINC complex in nuclear migration during myogenesis is well established (Zhang et al., 2010; Gimpel et al., 2017; Stroud et al., 2017), yet whether this importance persists for tissue maintenance is unclear. We still have a limited understanding of how myonuclei are integrated into the cytoskeleton in muscle fibers, how this is accomplished during the unique phenomenon of myonuclear addition, and finally, how this integration may change during adaptation, disease, or aging.

One of the primary challenges in studying the role of nuclear mechanotransduction in a specific cellular response is decoupling the mechanoresponse of the nucleus from cell surface/cytoplasmic signaling events. This can be accomplished by either performing assays on isolated nuclei (Guilluy and Burridge, 2015; Stephens et al., 2019), or via the more biologically relevant technique of restricting mechanical signals from reaching the nucleus. In practice, this can be done by expressing dominant-negative nesprin or SUN constructs (Lombardi et al., 2011; Uzer et al., 2018), which globally disrupt all LINC complexes, or via targeting of specific LINC complex or LINC-complex associated proteins (Staszewska et al., 2015; Tajik et al., 2016; Cosgrove et al., 2021).

Another significant challenge will be identifying mechanisms that control the specificity of the response. For example, if chromatin stretching can induce transcriptional activation, how can this be restricted to specific genes or loci? There may need to be additional layers of regulation, such as additional epigenetic modifications that modulate the response (Sun et al., 2020). Integrating genetic and biophysical methods 
with either advanced-tissue engineering approaches or novel mouse models will be necessary to study the causative effects of nuclear mechanotransduction on muscle mass and function. For the mouse models, utilizing inducible- and tissue-specific strains (Murach et al., 2020) will allow for separating developmental effects from those necessary for maintenance and adaptation during adulthood. Combining these approaches with recent advances in single-nuclear sequencing (Ding et al., 2020; Dos Santos et al., 2020; Petrany et al., 2020) and chromatin-accessibility technologies (Klein and Hainer, 2020) could allow for discovery of novel transcriptional and/or chromatin organization mechanisms. Moreover, recently developed LINC complex-based tension sensors (Arsenovic et al., 2016; Déjardin et al., 2020) could be implemented to quantify the amount of cytoskeleton-to-nucleus force transmission in muscle fibers. Lastly, as an alternative to experimental-based approaches, computational modeling has potential utility for the prediction of how various mechanical force-generating and transmitting structures in skeletal muscle contribute to nuclear mechanobiology (Mohammed et al., 2019).

Seminal work over the past 30 years has started to unravel the molecular details for how mechanical forces are transduced in skeletal muscle in order to control tissue mass and function. Nevertheless, the potential influence of nuclear mechanotransduction on directly modulating myonuclear organization and/or activity has been largely overlooked. Additional work is necessary to understand the precise role that cytoskeletal-nuclear force transmission has on the skeletal muscle transcriptome, and if so, how specificity in controlled. Furthermore, decoupling these events from cytoplasmic signaling events remains a challenge, as it is likely

\section{REFERENCES}

Al-Haboubi, T., Shumaker, D. K., Köser, J., Wehnert, M., and Fahrenkrog, B. (2011). Distinct association of the nuclear pore protein Nup153 with A- and B-type lamins. Nucleus 2, 500-509. doi: 10.4161/nucl.2.5.17913

Anno, T., Sakamoto, N., and Sato, M. (2012). Role of nesprin-1 in nuclear deformation in endothelial cells under static and uniaxial stretching conditions. Biochem. Biophys. Res. Commun. 424, 94-99. doi: 10.1016/j.bbrc.2012.06.073

Armstrong, D. D., and Esser, K. A. (2005). Wnt/ $\beta$-catenin signaling activates growth-control genes during overload-induced skeletal muscle hypertrophy. Am. J. Physiol. Cell Physiol. 289, C853-C859. doi: 10.1152/ajpcell.00093.2005

Armstrong, D. D., Wong, V. L., and Esser, K. A. (2006). Expression of $\beta$-catenin is necessary for physiological growth of adult skeletal muscle. Am. J. Physiol. Cell Physiol. 291, C185-C188. doi: 10.1152/ajpcell.00644.2005

Arsenovic, P. T., Ramachandran, I., Bathula, K., Zhu, R., Narang, J. D., Noll, N. A., et al. (2016). Nesprin-2G, a Component of the Nuclear LINC complex, is subject to myosin-dependent tension. Biophys. J. 110, 34-43. doi: 10.1016/j.bpj.2015.11. 014

Aureille, J., Buffière-Ribot, V., Harvey, B. E., Boyault, C., Pernet, L., Andersen, T., et al. (2019). Nuclear envelope deformation controls cell cycle progression in response to mechanical force. EMBO Rep. 20:e48084. doi: 10.15252/embr. 201948084

Bamman, M. M., Roberts, B. M., and Adams, G. R. (2018). Molecular regulation of exercise-induced muscle fiber hypertrophy. Cold Spring Harb. Perspect. Med. 8:a029751. doi: 10.1101/cshperspect.a029751

Banerjee, I., Zhang, J., Moore-Morris, T., Pfeiffer, E., Buchholz, K. S., Liu, A., et al. (2014). Targeted ablation of Nesprin 1 and Nesprin 2 from murine myocardium results in cardiomyopathy, altered nuclear morphology and inhibition of the that synergy between multiple mechanotransduction pathways is required to produce the appropriate response. We propose that nuclear mechanotransduction may provide an additional "fine-tuning" role for priming the muscle cell for the appropriate transcriptional response to mechanical stimuli (Tajik et al., 2016), or possibly serve to alter the mechanical properties of the nucleus to protect the genome from repeated mechanical stresses (Nava et al., 2020), ultimately serving as an integral link between mechanical loading and muscle mass regulation.

\section{AUTHOR CONTRIBUTIONS}

All authors listed have made a substantial, direct and intellectual contribution to the work, and approved it for publication.

\section{FUNDING}

This work was supported by funding from the Muscular Dystrophy Association (Career Development Grant; MDA603238) and the Dutch Cardiovascular Alliance (Talent Grant) awarded to TK.

\section{ACKNOWLEDGMENTS}

The authors apologize to the many colleagues whose work could not be cited due to space constraints. The authors thank Dr. Coen Ottenheijm and Mary Godec for their helpful discussion and feedback during the drafting of the manuscript.

biomechanical gene response. PLoS Genet. 10:e1004114. doi: 10.1371/journal. pgen.1004114

Barton, L. J., Soshnev, A. A., and Geyer, P. K. (2015). Networking in the nucleus: a spotlight on LEM-domain proteins. Curr. Opin. Cell Biol. 34, 1-8. doi: 10.1016/ j.ceb.2015.03.005

Becker, R., Leone, M., and Engel, F. B. (2020). Microtubule organization in striated muscle cells. Cells 9:1395. doi: 10.3390/cells9061395

Berk, J. M., Tifft, K. E., and Wilson, K. L. (2013). The nuclear envelope LEMdomain protein emerin. Nucleus 4, 298-314. doi: 10.4161/nucl.25751

Bodine, S. C., Stitt, T. N., Gonzalez, M., Kline, W. O., Stover, G. L., Bauerlein, R., et al. (2001). Akt/mTOR pathway is a crucial regulator of skeletal muscle hypertrophy and can prevent muscle atrophy in vivo. Nat. Cell Biol. 3, 10141019. doi: 10.1038/ncb1101-1014

Bouzid, T., Kim, E., Riehl, B. D., Esfahani, A. M., Rosenbohm, J., Yang, R., et al. (2019). The LINC complex, mechanotransduction, and mesenchymal stem cell function and fate. J. Biol. Eng. 13:68. doi: 10.1186/s13036-019-0197-9

Brack, A. S., Bildsoe, H., and Hughes, S. M. (2005). Evidence that satellite cell decrement contributes to preferential decline in nuclear number from large fibres during murine age-related muscle atrophy. J. Cell Sci. 118, 4813-4821. doi: 10.1242/jcs.0 2602

Bruusgaard, J. C., Liestøl, K., and Gundersen, K. (2006). Distribution of myonuclei and microtubules in live muscle fibers of young, middle-aged, and old mice. J. Appl. Physiol. 100, 2024-2030. doi: 10.1152/japplphysiol.00913.2005

Buxboim, A., Swift, J., Irianto, J., Spinler, K. R., Dingal, P. C. D. P., Athirasala, A., et al. (2014). Matrix elasticity regulates lamin-A,C phosphorylation and turnover with feedback to actomyosin. Curr. Biol. 24, 1909-1917. doi: 10.1016/ j.cub.2014.07.001 
Cosgrove, B. D., Loebel, C., Driscoll, T. P., Tsinman, T. K., Dai, E. N., Heo, S.-J., et al. (2021). Nuclear envelope wrinkling predicts mesenchymal progenitor cell mechano-response in 2D and 3D microenvironments. Biomaterials 270:120662. doi: 10.1016/j.biomaterials.2021.120662

Cramer, A. A. W., Prasad, V., Eftestøl, E., Song, T., Hansson, K.-A., Dugdale, H. F., et al. (2020). Nuclear numbers in syncytial muscle fibers promote size but limit the development of larger myonuclear domains. Nat. Commun. 11:6287. doi: 10.1038/s41467-020-20058-7

Crisp, M., Liu, Q., Roux, K., Rattner, J. B., Shanahan, C., Burke, B., et al. (2005). Coupling of the nucleus and cytoplasm: role of the LINC complex. J. Cell Biol. 172, 41-53. doi: 10.1083/jcb.200509124

Cristea, A., Qaisar, R., Edlund, P. K., Lindblad, J., Bengtsson, E., and Larsson, L. (2010). Effects of aging and gender on the spatial organization of nuclei in single human skeletal muscle cells. Aging Cell 9, 685-697. doi: 10.1111/j.1474-9726. 2010.00594.x

Déjardin, T., Carollo, P. S., Sipieter, F., Davidson, P. M., Seiler, C., Cuvelier, D., et al. (2020). Nesprins are mechanotransducers that discriminate epithelialmesenchymal transition programs. J. Cell Biol. 219:e201908036. doi: 10.1083/ jcb.201908036

Ding, J., Adiconis, X., Simmons, S. K., Kowalczyk, M. S., Hession, C. C., Marjanovic, N. D., et al. (2020). Systematic comparison of single-cell and singlenucleus RNA-sequencing methods. Nat. Biotechnol. 38, 737-746. doi: 10.1038/ s41587-020-0465-8

Donnaloja, F., Carnevali, F., Jacchetti, E., and Raimondi, M. T. (2020). Lamin A/C mechanotransduction in laminopathies. Cells 9:1306. doi: 10.3390/cells9051306

Donnaloja, F., Jacchetti, E., Soncini, M., and Raimondi, M. T. (2019). Mechanosensing at the nuclear envelope by nuclear pore complex stretch activation and its effect in physiology and pathology. Front. Physiol. 10:896. doi: 10.3389/fphys.2019.00896

Dos Santos, M., Backer, S., Saintpierre, B., Izac, B., Andrieu, M., Letourneur, F., et al. (2020). Single-nucleus RNA-seq and FISH identify coordinated transcriptional activity in mammalian myofibers. Nat. Commun. 11:5102. doi: 10.1038/s41467-020-18789-8

Driscoll, T. P., Cosgrove, B. D., Heo, S.-J., Shurden, Z. E., and Mauck, R. L. (2015). Cytoskeletal to nuclear strain transfer regulates YAP signaling in mesenchymal stem cells. Biophys. J. 108, 2783-2793. doi: 10.1016/j.bpj.2015.05.010

Earle, A. J., Kirby, T. J., Fedorchak, G. R., Isermann, P., Patel, J., Iruvanti, S., et al. (2020). Mutant lamins cause nuclear envelope rupture and DNA damage in skeletal muscle cells. Nat. Mater. 19, 464-473. doi: 10.1038/s41563-019-0563-5

Elosegui-Artola, A., Andreu, I., Beedle, A. E. M., Lezamiz, A., Uroz, M., Kosmalska, A. J., et al. (2017). Force triggers Yap nuclear entry by regulating transport across nuclear pores. Cell 171, 1397.e14-1410.e14. doi: 10.1016/j.cell.2017.10.008

Enyedi, B., Jelcic, M., and Niethammer, P. (2016). The cell nucleus serves as a mechanotransducer of tissue damage-induced inflammation. Cell 165, 11601170. doi: 10.1016/j.cell.2016.04.016

Gesson, K., Vidak, S., and Foisner, R. (2014). Lamina-associated polypeptide (LAP) $2 \alpha$ and nucleoplasmic lamins in adult stem cell regulation and disease. Semin. Cell Dev. Biol. 29, 116-124. doi: 10.1016/j.semcdb.2013.12.009

Gilbert, H. T. J., Mallikarjun, V., Dobre, O., Jackson, M. R., Pedley, R., Gilmore, A. P., et al. (2019). Nuclear decoupling is part of a rapid protein-level cellular response to high-intensity mechanical loading. Nat. Commun. 10:4149. doi: 10.1038/s41467-019-11923-1

Gimpel, P., Lee, Y. L., Sobota, R. M., Calvi, A., Koullourou, V., Patel, R., et al. (2017). Nesprin-1 $\alpha$-dependent microtubule nucleation from the nuclear envelope via Akap450 is necessary for nuclear positioning in muscle cells. Curr. Biol. 27, 2999.e9-3009.e9. doi: 10.1016/j.cub.2017.08.031

Goldman, R. D., Shumaker, D. K., Erdos, M. R., Eriksson, M., Goldman, A. E., Gordon, L. B., et al. (2004). Accumulation of mutant lamin A causes progressive changes in nuclear architecture in Hutchinson-Gilford progeria syndrome. Proc. Natl. Acad. Sci. U.S.A. 101, 8963-8968. doi: 10.1073/pnas.0402943101

Goodman, C. A., Dietz, J. M., Jacobs, B. L., McNally, R. M., You, J.-S., and Hornberger, T. A. (2015). Yes-Associated Protein is up-regulated by mechanical overload and is sufficient to induce skeletal muscle hypertrophy. FEBS Lett. 589, 1491-1497. doi: 10.1016/j.febslet.2015.04.047

Graber, T. G., Fry, C. S., Brightwell, C. R., Moro, T., Maroto, R., Bhattarai, N., et al. (2019). Skeletal muscle-specific knockout of DEP domain containing 5 protein increases mTORC1 signaling, muscle cell hypertrophy, and mitochondrial respiration. J. Biol. Chem. 294, 4091-4102. doi: 10.1074/jbc.RA118. 005970
Graham, D. M., Andersen, T., Sharek, L., Uzer, G., Rothenberg, K., Hoffman, B. D., et al. (2018). Enucleated cells reveal differential roles of the nucleus in cell migration, polarity, and mechanotransduction. J. Cell Biol. 217, 895-914. doi: $10.1083 /$ jcb. 201706097

Guilluy, C., and Burridge, K. (2015). Nuclear mechanotransduction: forcing the nucleus to respond. Nucleus 6, 19-22. doi: 10.1080/19491034.2014.1001705

Guilluy, C., Osborne, L. D., Van Landeghem, L., Sharek, L., Superfine, R., Garcia-Mata, R., et al. (2014). Isolated nuclei adapt to force and reveal a mechanotransduction pathway within the nucleus. Nat. Cell Biol. 16, 376-381. doi: $10.1038 /$ ncb2927

Gundersen, G. G., and Worman, H. J. (2013). Nuclear positioning. Cell 152, 1376-1389. doi: 10.1016/j.cell.2013.02.031

Hansson, K.-A., Eftestøl, E., Bruusgaard, J. C., Juvkam, I., Cramer, A. W., MaltheSørenssen, A., et al. (2020). Myonuclear content regulates cell size with similar scaling properties in mice and humans. Nat. Commun. 11:6288. doi: 10.1038/ s41467-020-20057-8

Hao, H., and Starr, D. A. (2019). SUN/KASH interactions facilitate force transmission across the nuclear envelope. Nucleus 10, 73-80. doi: 10.1080/ 19491034.2019.1595313

Haque, F., Lloyd, D. J., Smallwood, D. T., Dent, C. L., Shanahan, C. M., Fry, A. M., et al. (2006). SUN1 interacts with nuclear lamin a and cytoplasmic nesprins to provide a physical connection between the nuclear lamina and the cytoskeleton. Mol. Cell. Biol. 26, 3738-3751. doi: 10.1128/MCB.26.10.3738-3751.2006

Haque, F., Mazzeo, D., Patel, J. T., Smallwood, D. T., Ellis, J. A., Shanahan, C. M., et al. (2010). Mammalian SUN protein interaction networks at the inner nuclear membrane and their role in laminopathy disease processes. J. Biol. Chem. 285, 3487-3498. doi: 10.1074/jbc.M109.071910

Heffler, J., Shah, P. P., Robison, P., Phyo, S., Veliz, K., Uchida, K., et al. (2020). A Balance between intermediate filaments and microtubules maintains nuclear architecture in the cardiomyocyte. Circ. Res. 126, e10-e26. doi: 10.1161/ CIRCRESAHA.119.315582

Heller, S. A., Shih, R., Kalra, R., and Kang, P. B. (2020). Emery-Dreifuss muscular dystrophy. Muscle Nerve 61, 436-448. doi: 10.1002/mus.26782

Ho, C. Y., Jaalouk, D. E., Vartiainen, M. K., and Lammerding, J. (2013). Lamin A/C and emerin regulate MKL1-SRF activity by modulating actin dynamics. Nature 497, 507-511. doi: 10.1038/nature 12105

Hoffman, L. M., Smith, M. A., Jensen, C. C., Yoshigi, M., Blankman, E., Ullman, K. S., et al. (2020). Mechanical stress triggers nuclear remodeling and the formation of transmembrane actin nuclear lines with associated nuclear pore complexes. Mol. Biol. Cell 31, 1774-1787. doi: 10.1091/mbc.E19-01-0027

Holt, I., Fuller, H. R., Lam, L. T., Sewry, C. A., Shirran, S. L., Zhang, Q., et al. (2019). Nesprin-1-alpha2 associates with kinesin at myotube outer nuclear membranes, but is restricted to neuromuscular junction nuclei in adult muscle. Sci. Rep. 9:14202. doi: 10.1038/s41598-019-50728-6

Horn, H. F., Brownstein, Z., Lenz, D. R., Shivatzki, S., Dror, A. A., DaganRosenfeld, O., et al. (2013a). The LINC complex is essential for hearing. J. Clin. Invest. 123, 740-750. doi: 10.1172/JCI66911

Horn, H. F., Kim, D. I., Wright, G. D., Wong, E. S. M., Stewart, C. L., Burke, B., et al. (2013b). A mammalian KASH domain protein coupling meiotic chromosomes to the cytoskeleton. J. Cell Biol. 202, 1023-1039. doi: 10.1083/jcb.201304004

Hunt, L. C., Schadeberg, B., Stover, J., Haugen, B., Pagala, V., Wang, Y.-D., et al. (2021). Antagonistic control of myofiber size and muscle protein quality control by the ubiquitin ligase UBR4 during aging. Nat. Commun. 12:1418. doi: 10 . 1038/s41467-021-21738-8

Ihalainen, T. O., Aires, L., Herzog, F. A., Schwartlander, R., Moeller, J., and Vogel, V. (2015). Differential basal-to-apical accessibility of lamin A/C epitopes in the nuclear lamina regulated by changes in cytoskeletal tension. Nat. Mater. 14, 1252-1261. doi: 10.1038/nmat4389

Ikegami, K., Secchia, S., Almakki, O., Lieb, J. D., and Moskowitz, I. P. (2020). Phosphorylated lamin $\mathrm{A} / \mathrm{C}$ in the nuclear interior binds active enhancers associated with abnormal transcription in progeria. Dev. Cell 52, 699.e11713.e11. doi: 10.1016/j.devcel.2020.02.011

Ivorra, C., Kubicek, M., González, J. M., Sanz-González, S. M., Álvarez-Barrientos, A., O'Connor, J.-E., et al. (2006). A mechanism of AP-1 suppression through interaction of c-Fos with lamin A/C. Genes Dev. 20, 307-320. doi: 10.1101/gad. 349506

Iyer, S. R., Hsia, R.-C., Folker, E. S., and Lovering, R. M. (2021). Age-dependent changes in nuclear-cytoplasmic signaling in skeletal muscle. Exp. Gerontol. 150, 111338. doi: 10.1016/j.exger.2021.111338 
Jabre, S., Hleihel, W., and Coirault, C. (2021). Nuclear mechanotransduction in skeletal muscle. Cells 10:318. doi: 10.3390/cells10020318

Jacques, M., Hiam, D., Craig, J., Barrès, R., Eynon, N., and Voisin, S. (2019). Epigenetic changes in healthy human skeletal muscle following exercisea systematic review. Epigenetics 14, 633-648. doi: 10.1080/15592294.2019. 1614416

Jahed, Z., Hao, H., Thakkar, V., Vu, U. T., Valdez, V. A., Rathish, A., et al. (2019). Role of KASH domain lengths in the regulation of LINC complexes. Mol. Biol. Cell 30, 2076-2086. doi: 10.1091/mbc.E19-02-0079

Janin, A., and Gache, V. (2018). Nesprins and lamins in health and diseases of cardiac and skeletal muscles. Front. Physiol. 9:1277. doi: 10.3389/fphys.2018. 01277

Janota, C. S., Calero-Cuenca, F. J., and Gomes, E. R. (2020). The role of the cell nucleus in mechanotransduction. Curr. Opin. Cell Biol. 63, 204-211. doi: 10.1016/j.ceb.2020.03.001

Janssen, A., Colmenares, S. U., and Karpen, G. H. (2018). Heterochromatin: guardian of the genome. Annu. Rev. Cell Dev. Biol. 34, 265-288. doi: 10.1146/ annurev-cellbio-100617-062653

Joanisse, S., Lim, C., McKendry, J., Mcleod, J. C., Stokes, T., and Phillips, S. M. (2020). Recent advances in understanding resistance exercise training-induced skeletal muscle hypertrophy in humans. F1000Research 9:141. doi: 10.12688/ f1000research.21588.1

Jorgenson, K. W., Phillips, S. M., and Hornberger, T. A. (2020). Identifying the structural adaptations that drive the mechanical load-induced growth of skeletal muscle: a scoping review. Cells 9:1658. doi: 10.3390/cells9071658

Kerr, J. P., Robison, P., Shi, G., Bogush, A. I., Kempema, A. M., Hexum, J. K., et al. (2015). Detyrosinated microtubules modulate mechanotransduction in heart and skeletal muscle. Nat. Commun. 6:8526. doi: 10.1038/ncomms9526

Ketema, M., Wilhelmsen, K., Kuikman, I., Janssen, H., Hodzic, D., and Sonnenberg, A. (2007). Requirements for the localization of nesprin-3 at the nuclear envelope and its interaction with plectin. J. Cell Sci. 120, 3384-3394. doi: 10. $1242 /$ jcs. 014191

Kirby, T. J. (2019). Mechanosensitive pathways controlling translation regulatory processes in skeletal muscle and implications for adaptation. J. Appl. Physiol. 127, 608-618. doi: 10.1152/japplphysiol.01031.2018

Kirby, T. J., and Lammerding, J. (2018). Emerging views of the nucleus as a cellular mechanosensor. Nat. Cell Biol. 20, 373-381. doi: 10.1038/s41556-018-0038-y

Kittisopikul, M., Shimi, T., Tatli, M., Tran, J. R., Zheng, Y., Medalia, O., et al. (2021). Computational analyses reveal spatial relationships between nuclear pore complexes and specific lamins. J. Cell Biol. 220, e202007082. doi: 10.1083/ jcb.202007082

Klein, D. C., and Hainer, S. J. (2020). Genomic methods in profiling DNA accessibility and factor localization. Chromosome Res. 28, 69-85. doi: 10.1007/ s10577-019-09619-9

Knockenhauer, K. E., and Schwartz, T. U. (2016). The nuclear pore complex as a flexible and dynamic gate. Cell 164, 1162-1171. doi: 10.1016/j.cell.2016.01.034

Kochin, V., Shimi, T., Torvaldson, E., Adam, S. A., Goldman, A., Pack, C.-G., et al. (2014). Interphase phosphorylation of lamin A. J. Cell Sci. 127, 2683-2696. doi: $10.1242 /$ jcs. 141820

Kozono, T., Tadahira, K., Okumura, W., Itai, N., Tamura-Nakano, M., Dohi, T., et al. (2018). Jaw1/LRMP has a role in maintaining nuclear shape via interaction with SUN proteins. J. Biochem. 164, 303-311. doi: 10.1093/jb/mvy053

Lammerding, J., Fong, L. G., Ji, J. Y., Reue, K., Stewart, C. L., Young, S. G., et al. (2006). Lamins A and C but not lamin B1 regulate nuclear mechanics*. J. Biol. Chem. 281, 25768-25780. doi: 10.1074/jbc.M513511200

Le, H. Q., Ghatak, S., Yeung, C.-Y. C., Tellkamp, F., Günschmann, C., Dieterich, C., et al. (2016). Mechanical regulation of transcription controls Polycombmediated gene silencing during lineage commitment. Nat. Cell Biol. 18, 864875. doi: $10.1038 /$ ncb3387

Lei, K., Zhang, X., Ding, X., Guo, X., Chen, M., Zhu, B., et al. (2009). SUN1 and SUN2 play critical but partially redundant roles in anchoring nuclei in skeletal muscle cells in mice. Proc. Natl. Acad. Sci. U.S.A. 106, 10207-10212. doi: 10.1073/pnas.0812037106

Lim, C., Shimizu, J., Kawano, F., Kim, H. J., and Kim, C. K. (2020). Adaptive responses of histone modifications to resistance exercise in human skeletal muscle. PLoS One 15:e0231321. doi: 10.1371/journal.pone.0231321

Liu, J., Huang, Z.-P., Nie, M., Wang, G., Silva, W. J., Yang, Q., et al. (2020). Regulation of myonuclear positioning and muscle function by the skeletal muscle-specific CIP protein. Proc. Natl. Acad. Sci. U.S.A. 117, 19254-19265. doi: 10.1073/pnas.1922911117

Liu, Q., Pante, N., Misteli, T., Elsagga, M., Crisp, M., Hodzic, D., et al. (2007). Functional association of Sun1 with nuclear pore complexes. J. Cell Biol. 178, 785-798. doi: 10.1083/jcb.200704108

Lomakin, A. J., Cattin, C. J., Cuvelier, D., Alraies, Z., Molina, M., Nader, G. P. F., et al. (2020). The nucleus acts as a ruler tailoring cell responses to spatial constraints. Science 370:eaba2894. doi: 10.1126/science.aba2894

Lombardi, M. L., Jaalouk, D. E., Shanahan, C. M., Burke, B., Roux, K. J., and Lammerding, J. (2011). The interaction between nesprins and sun proteins at the nuclear envelope is critical for force transmission between the nucleus and cytoskeleton. J. Biol. Chem. 286, 26743-26753. doi: 10.1074/jbc.M111.233700

Malone, C. J., Fixsen, W. D., Horvitz, H. R., and Han, M. (1999). UNC-84 localizes to the nuclear envelope and is required for nuclear migration and anchoring during C. elegans development. Development 126, 3171-3181. doi: 10.1242/dev. 126.14.3171

Maniotis, A. J., Chen, C. S., and Ingber, D. E. (1997). Demonstration of mechanical connections between integrins, cytoskeletal filaments, and nucleoplasm that stabilize nuclear structure. Proc. Natl. Acad. Sci. U.S.A. 94, 849-854. doi: 10. 1073/pnas.94.3.849

Marcotte, G. R., West, D. W. D., and Baar, K. (2015). The molecular basis for load-induced skeletal muscle hypertrophy. Calcif. Tissue Int. 96, 196-210. doi: 10.1007/s00223-014-9925-9

Markiewicz, E., Tilgner, K., Barker, N., van de Wetering, M., Clevers, H., Dorobek, M., et al. (2006). The inner nuclear membrane protein Emerin regulates $\beta$ catenin activity by restricting its accumulation in the nucleus. EMBO J. 25 , 3275-3285. doi: 10.1038/sj.emboj.7601230

Maurer, M., and Lammerding, J. (2019). The driving force: nuclear mechanotransduction in cellular function, fate, and disease. Annu. Rev. Biomed. Eng. 21, 443-468. doi: 10.1146/annurev-bioeng-060418-052139

McCarthy, J. J., Mula, J., Miyazaki, M., Erfani, R., Garrison, K., Farooqui, A. B., et al. (2011). Effective fiber hypertrophy in satellite cell-depleted skeletal muscle. Development 138, 3657-3666. doi: 10.1242/dev.068858

McGee, S. L., and Walder, K. R. (2017). Exercise and the skeletal muscle epigenome. Cold Spring Harb. Perspect. Med. 7:a029876. doi: 10.1101/cshperspect.a029876

McGlory, C., and Phillips, S. M. (2015). "Exercise and the regulation of skeletal muscle hypertrophy," in Progress in Molecular Biology and Translational Science, ed. D. B. Teplow (Amsterdam: Elsevier), 153-173. doi: 10.1016/bs.pmbts.2015. 06.018

Mislow, J. M. K., Holaska, J. M., Kim, M. S., Lee, K. K., Segura-Totten, M., Wilson, K. L., et al. (2002). Nesprin-1 $\alpha$ self-associates and binds directly to emerin and lamin A in vitro. FEBS Lett. 525, 135-140. doi: 10.1016/S0014-5793(02)03105-8

Mohammed, D., Versaevel, M., Bruyère, C., Alaimo, L., Luciano, M., Vercruysse, E., et al. (2019). Innovative tools for mechanobiology: unraveling outside-in and inside-out mechanotransduction. Front. Bioeng. Biotechnol. 7:162. doi: 10.3389/ fbioe.2019.00162

Murach, K. A., Fry, C. S., Kirby, T. J., Jackson, J. R., Lee, J. D., White, S. H., et al. (2017). Starring or supporting role? Satellite cells and skeletal muscle fiber size regulation. Physiology 33, 26-38. doi: 10.1152/physiol.00019.2017

Murach, K. A., McCarthy, J. J., Peterson, C. A., and Dungan, C. M. (2020). Making Mice Mighty: recent advances in translational models of load-induced muscle hypertrophy. J. Appl. Physiol. Bethesda Md 129, 516-521. doi: 10.1152/ japplphysiol.00319.2020

Murgia, M., Toniolo, L., Nagaraj, N., Ciciliot, S., Vindigni, V., Schiaffino, S., et al. (2017). Single muscle fiber proteomics reveals fiber-type-specific features of human muscle aging. Cell Rep. 19, 2396-2409. doi: 10.1016/j.celrep.2017.05.054

Nava, M. M., Miroshnikova, Y. A., Biggs, L. C., Whitefield, D. B., Metge, F., Boucas, J., et al. (2020). Heterochromatin-driven nuclear softening protects the genome against mechanical stress-induced damage. Cell 181, 800.e22-817.e22. doi: 10.1016/j.cell.2020.03.052

Neumann, S., Schneider, M., Daugherty, R. L., Gottardi, C. J., Eming, S. A., Beijer, A., et al. (2010). Nesprin-2 interacts with $\alpha$-catenin and regulates Wnt signaling at the nuclear envelope. J. Biol. Chem. 285, 34932-34938. doi: 10.1074/jbc. M110.119651

Palmisano, M. G., Bremner, S. N., Hornberger, T. A., Meyer, G. A., Domenighetti, A. A., Shah, S. B., et al. (2015). Skeletal muscle intermediate filaments form a stress-transmitting and stress-signaling network. J. Cell Sci. 128, 219-224. doi: $10.1242 /$ jcs. 142463 
Petrany, M. J., Swoboda, C. O., Sun, C., Chetal, K., Chen, X., Weirauch, M. T., et al. (2020). Single-nucleus RNA-seq identifies transcriptional heterogeneity in multinucleated skeletal myofibers. Nat. Commun. 11:6374. doi: 10.1038/ s41467-020-20063-w

Petridou, N. I., Spiró, Z., and Heisenberg, C.-P. (2017). Multiscale force sensing in development. Nat. Cell Biol. 19, 581-588. doi: 10.1038/ncb3524

Phillips, B. E., Williams, J. P., Gustafsson, T., Bouchard, C., Rankinen, T., Knudsen, S., et al. (2013). Molecular Networks of Human Muscle Adaptation to Exercise and Age. PLoS Genet. 9:e1003389. doi: 10.1371/journal.pgen.1003389

Piccus, R., and Brayson, D. (2020). The nuclear envelope: LINCing tissue mechanics to genome regulation in cardiac and skeletal muscle. Biol. Lett. 16:20200302. doi: 10.1098/rsbl.2020.0302

Piekarowicz, K., Machowska, M., Dzianisava, V., and Rzepecki, R. (2019). Hutchinson-gilford progeria syndrome-current status and prospects for gene therapy treatment. Cells 8:88. doi: 10.3390/cells8020088

Psilander, N., Eftestøl, E., Cumming, K. T., Juvkam, I., Ekblom, M. M., Sunding, K., et al. (2019). Effects of training, detraining, and retraining on strength, hypertrophy, and myonuclear number in human skeletal muscle. J. Appl. Physiol. 126, 1636-1645. doi: 10.1152/japplphysiol.00917.2018

Puckelwartz, M. J., Kessler, E. J., Kim, G., DeWitt, M. M., Zhang, Y., Earley, J. U., et al. (2010). Nesprin-1 mutations in human and murine cardiomyopathy. J. Mol. Cell. Cardiol. 48, 600-608. doi: 10.1016/j.yjmcc.2009.11.006

Pulupa, J., Prior, H., Johnson, D. S., and Simon, S. M. (2020). Conformation of the nuclear pore in living cells is modulated by transport state. eLife 9:e60654. doi: 10.7554/eLife.60654

Raffaello, A., Milan, G., Masiero, E., Carnio, S., Lee, D., Lanfranchi, G., et al. (2010). JunB transcription factor maintains skeletal muscle mass and promotes hypertrophy. J. Cell Biol. 191, 101-113. doi: 10.1083/jcb.201001136

Rajgor, D., and Shanahan, C. M. (2013). Nesprins: from the nuclear envelope and beyond. Expert Rev. Mol. Med. 15:e5. doi: 10.1017/erm.2013.6

Röhrl, J. M., Arnold, R., and Djabali, K. (2021). Nuclear pore complexes cluster in dysmorphic nuclei of normal and progeria cells during replicative senescence. Cells 10:153. doi: 10.3390/cells10010153

Roux, K. J., Crisp, M. L., Liu, Q., Kim, D., Kozlov, S., Stewart, C. L., et al. (2009). Nesprin 4 is an outer nuclear membrane protein that can induce kinesinmediated cell polarization. Proc. Natl. Acad. Sci. U.S.A. 106, 2194-2199. doi: 10.1073/pnas.0808602106

Samson, C., Petitalot, A., Celli, F., Herrada, I., Ropars, V., Le Du, M.-H., et al. (2018). Structural analysis of the ternary complex between lamin A/C, BAF and emerin identifies an interface disrupted in autosomal recessive progeroid diseases. Nucleic Acids Res. 46, 10460-10473. doi: 10.1093/nar/gky736

Sartori, R., Romanello, V., and Sandri, M. (2021). Mechanisms of muscle atrophy and hypertrophy: implications in health and disease. Nat. Commun. 12:330. doi: 10.1038/s41467-020-20123-1

Setiawan, I., Sanjaya, A., Lesmana, R., Yen, P. M., and Goenawan, H. (2021). Hippo pathway effectors YAP and TAZ and their association with skeletal muscle ageing. J. Physiol. Biochem. 77, 63-73. doi: 10.1007/s13105-021-00787-z

Shin, J.-Y., Dour, C. L., Sera, F., Iwata, S., Homma, S., Joseph, L. C., et al. (2014). Depletion of lamina-associated polypeptide 1 from cardiomyocytes causes cardiac dysfunction in mice. Nucleus 5, 260-268. doi: 10.4161/nucl.29227

Shin, J.-Y., Méndez-López, I., Hong, M., Wang, Y., Tanji, K., Wu, W., et al. (2017). Lamina-associated polypeptide 1 is dispensable for embryonic myogenesis but required for postnatal skeletal muscle growth. Hum. Mol. Genet. 26, 65-78. doi: $10.1093 / \mathrm{hmg} / \mathrm{ddw} 368$

Shin, J.-Y., Méndez-López, I., Wang, Y., Hays, A. P., Tanji, K., Lefkowitch, J. H., et al. (2013). Lamina-associated polypeptide-1 interacts with the muscular dystrophy protein emerin and is essential for skeletal muscle maintenance. Dev. Cell 26, 591-603. doi: 10.1016/j.devcel.2013.08.012

Snijders, T., Nederveen, J. P., McKay, B. R., Joanisse, S., Verdijk, L. B., van Loon, L. J. C., et al. (2015). Satellite cells in human skeletal muscle plasticity. Front. Physiol. 6:283. doi: 10.3389/fphys.2015.00283

Solagna, F., Nogara, L., Dyar, K. A., Greulich, F., Mir, A. A., Türk, C., et al. (2020). Exercise-dependent increases in protein synthesis are accompanied by chromatin modifications and increased MRTF-SRF signalling. Acta Physiol. 230, e13496. doi: 10.1111/apha.13496

Solovei, I., Wang, A. S., Thanisch, K., Schmidt, C. S., Krebs, S., Zwerger, M., et al. (2013). LBR and lamin A/C sequentially tether peripheral heterochromatin and inversely regulate differentiation. Cell 152, 584-598. doi: 10.1016/j.cell.2013.01. 009

Staszewska, I., Fischer, I., and Wiche, G. (2015). Plectin isoform 1-dependent nuclear docking of desmin networks affects myonuclear architecture and expression of mechanotransducers. Hum. Mol. Genet. 24, 7373-7389. doi: 10. 1093/hmg/ddv438

Stephens, A. D., Banigan, E. J., Adam, S. A., Goldman, R. D., and Marko, J. F. (2017). Chromatin and lamin A determine two different mechanical response regimes of the cell nucleus. Mol. Biol. Cell 28, 1984-1996. doi: 10.1091/mbc.e1609-0653

Stephens, A. D., Liu, P. Z., Kandula, V., Chen, H., Almassalha, L. M., Herman, C., et al. (2019). Physicochemical mechanotransduction alters nuclear shape and mechanics via heterochromatin formation. Mol. Biol. Cell 30, 2320-2330. doi: 10.1091/mbc.E19-05-0286

Stokes, T., Timmons, J. A., Crossland, H., Tripp, T. R., Murphy, K., McGlory, C., et al. (2020). Molecular transducers of human skeletal muscle remodeling under different loading states. Cell Rep. 32:7980. doi: 10.1016/j.celrep.2020.107980

Stroud, M. J., Feng, W., Zhang, J., Veevers, J., Fang, X., Gerace, L., et al. (2017). Nesprin $1 \alpha 2$ is essential for mouse postnatal viability and nuclear positioning in skeletal muscle. J. Cell Biol. 216, 1915-1924. doi: 10.1083/jcb.201612128

Sun, J., Chen, J., Mohagheghian, E., and Wang, N. (2020). Force-induced gene up-regulation does not follow the weak power law but depends on H3K9 demethylation. Sci. Adv. 6:eaay9095. doi: 10.1126/sciadv.aay9095

Swift, J., Ivanovska, I. L., Buxboim, A., Harada, T., Dingal, P. C. D. P., Pinter, J., et al. (2013). Nuclear Lamin-A scales with tissue stiffness and enhances matrixdirected differentiation. Science 341:1240104. doi: 10.1126/science.1240104

Tajik, A., Zhang, Y., Wei, F., Sun, J., Jia, Q., Zhou, W., et al. (2016). Transcription upregulation via force-induced direct stretching of chromatin. Nat. Mater. 15, 1287-1296. doi: 10.1038/nmat4729

Tilgner, K., Wojciechowicz, K., Jahoda, C., Hutchison, C., and Markiewicz, E. (2009). Dynamic complexes of A-type lamins and emerin influence adipogenic capacity of the cell via nucleocytoplasmic distribution of $\beta$-catenin. J. Cell Sci. 122, 401-413. doi: 10.1242/jcs.026179

Uzer, G., Bas, G., Sen, B., Xie, Z., Birks, S., Olcum, M., et al. (2018). Sun-mediated mechanical LINC between nucleus and cytoskeleton regulates $\beta$ catenin nuclear access. J. Biomech. 74, 32-40. doi: 10.1016/j.jbiomech.2018.04.013

van Steensel, B., and Belmont, A. S. (2017). Lamina-associated domains: links with chromosome architecture, heterochromatin, and gene repression. Cell 169, 780-791. doi: 10.1016/j.cell.2017.04.022

Venturini, V., Pezzano, F., Castro, F. C., Häkkinen, H.-M., Jiménez-Delgado, S., Colomer-Rosell, M., et al. (2020). The nucleus measures shape changes for cellular proprioception to control dynamic cell behavior. Science 370:eaba2644. doi: 10.1126/science.aba2644

Vergarajauregui, S., Becker, R., Steffen, U., Sharkova, M., Esser, T., Petzold, J., et al. (2020). AKAP6 orchestrates the nuclear envelope microtubule-organizing center by linking golgi and nucleus via AKAP9. eLife 9:e61669. doi: 10.7554/ eLife.61669

Walden, F. V., Rea, M., Mobley, C. B., Fondufe-Mittendorf, Y., McCarthy, J. J., Peterson, C. A., et al. (2020). The myonuclear DNA methylome in response to an acute hypertrophic stimulus. Epigenetics 15, 1151-1162. doi: 10.1080/ 15592294.2020.1755581

Watt, K. I., Goodman, C. A., Hornberger, T. A., and Gregorevic, P. (2018). The hippo signaling pathway in the regulation of skeletal muscle mass and function. Exerc. Sport Sci. Rev. 46, 92-96. doi: 10.1249/JES.0000000000000142

Watt, K. I., Turner, B. J., Hagg, A., Zhang, X., Davey, J. R., Qian, H., et al. (2015). The Hippo pathway effector YAP is a critical regulator of skeletal muscle fibre size. Nat. Commun. 6:6048. doi: 10.1038/ncomms7048

Wheeler, M. A., Davies, J. D., Zhang, Q., Emerson, L. J., Hunt, J., Shanahan, C. M., et al. (2007). Distinct functional domains in nesprin-1alpha and nesprin-2beta bind directly to emerin and both interactions are disrupted in X-linked EmeryDreifuss muscular dystrophy. Exp. Cell Res. 313, 2845-2857. doi: 10.1016/j. yexcr.2007.03.025

Wiche, G., Osmanagic-Myers, S., and Castañón, M. J. (2015). Networking and anchoring through plectin: a key to IF functionality and mechanotransduction. Curr. Opin. Cell Biol. 32, 21-29. doi: 10.1016/j.ceb.2014.10.002

Wilhelmsen, K., Litjens, S. H. M., Kuikman, I., Tshimbalanga, N., Janssen, H., van den Bout, I., et al. (2005). Nesprin-3, a novel outer nuclear membrane protein, 
associates with the cytoskeletal linker protein plectin. J. Cell Biol. 171, 799-810. doi: $10.1083 /$ jcb. 200506083

Wilson, M. H., and Holzbaur, E. L. F. (2015). Nesprins anchor kinesin-1 motors to the nucleus to drive nuclear distribution in muscle cells. Development 142, 218-228. doi: 10.1242/dev.114769

Winje, I. M., Bengtsen, M., Eftestøl, E., Juvkam, I., Bruusgaard, J. C., and Gundersen, K. (2018). Specific labelling of myonuclei by an antibody against pericentriolar material 1 on skeletal muscle tissue sections. Acta Physiol. 223:e13034. doi: 10.1111/apha.13034

Wong, X., Loo, T.-H., and Stewart, C. L. (2021). LINC complex regulation of genome organization and function. Curr. Opin. Genet. Dev. 67, 130-141. doi: 10.1016/j.gde.2020.12.007

Xie, W., Chojnowski, A., Boudier, T., Lim, J. S. Y., Ahmed, S., Ser, Z., et al. (2016). A-type lamins form distinct filamentous networks with differential nuclear pore complex associations. Curr. Biol. 26, 2651-2658. doi: 10.1016/j.cub.2016.07.049

Yoshihara, T., Machida, S., Tsuzuki, T., Kakigi, R., Chang, S., Sugiura, T., et al. (2019). Age-related changes in histone modification in rat gastrocnemius muscle. Exp. Gerontol. 125, 110658. doi: 10.1016/j.exger.2019.110658

You, J.-S., Mcnally, R. M., Jacobs, B. L., Privett, R. E., Gundermann, D. M., Lin, K.$\mathrm{H}$., et al. (2019). The role of raptor in the mechanical load-induced regulation of mTOR signaling, protein synthesis, and skeletal muscle hypertrophy. FASEB J. 33, 4021-4034. doi: 10.1096/fj.201801653RR

Zhang, J., Felder, A., Liu, Y., Guo, L. T., Lange, S., Dalton, N. D., et al. (2010). Nesprin 1 is critical for nuclear positioning and anchorage. Hum. Mol. Genet. 19, 329-341. doi: 10.1093/hmg/ddp499

Zhang, Q., Ragnauth, C. D., Skepper, J. N., Worth, N. F., Warren, D. T., Roberts, R. G., et al. (2005). Nesprin-2 is a multi-isomeric protein that binds lamin and emerin at the nuclear envelope and forms a subcellular network in skeletal muscle. J. Cell Sci. 118, 673-687. doi: 10.1242/jcs.01642

Zhou, C., Li, C., Zhou, B., Sun, H., Koullourou, V., Holt, I., et al. (2017). Novel nesprin-1 mutations associated with dilated cardiomyopathy cause nuclear envelope disruption and defects in myogenesis. Hum. Mol. Genet. 26, 22582276. doi: 10.1093/hmg/ddx116

Zhou, C., Rao, L., Shanahan, C. M., and Zhang, Q. (2018). Nesprin-1/2: roles in nuclear envelope organisation, myogenesis and muscle disease. Biochem. Soc. Trans. 46, 311-320. doi: 10.1042/BST20170149

Zhou, J., So, K. K., Li, Y., Li, Y., Yuan, J., Ding, Y., et al. (2019). Elevated H3K27ac in aged skeletal muscle leads to increase in extracellular matrix and fibrogenic conversion of muscle satellite cells. Aging Cell 18:e12996. doi: 10.1111/acel. 12996

Zhu, R., Antoku, S., and Gundersen, G. G. (2017). Centrifugal displacement of nuclei reveals multiple LINC complex mechanisms for homeostatic nuclear positioning. Curr. Biol. CB 27, 3097.e5-3110.e5. doi: 10.1016/j.cub.2017.08.073

Conflict of Interest: The authors declare that the research was conducted in the absence of any commercial or financial relationships that could be construed as a potential conflict of interest.

Copyright (C) 2021 van Ingen and Kirby. This is an open-access article distributed under the terms of the Creative Commons Attribution License (CC BY). The use, distribution or reproduction in other forums is permitted, provided the original author(s) and the copyright owner(s) are credited and that the original publication in this journal is cited, in accordance with accepted academic practice. No use, distribution or reproduction is permitted which does not comply with these terms. 